\title{
The Use of Cellobiose and Fructooligosaccharide on Growth and Stability of Bifidobacterium infantis in Fermented Milk
}

\author{
Mimoza Basholli-Salihu, ${ }^{1,2 *}$, Monika Mueller ${ }^{1}$, Frank M. Unger ${ }^{1}$, Helmut Viernstein ${ }^{1}$ \\ ${ }^{1}$ Department of Pharmaceutical Technology and Biopharmaceutics, University of Vienna, Vienna, Austria; ${ }^{2}$ Department of Pharmacy, \\ Faculty of Medicine, University of Prishtina, Prishtina, Kosova. \\ Email: ${ }^{*}$ mbasholli@yahoo.com
}

Received November $3^{\text {rd }}, 2013$; revised December $3^{\text {rd }}, 2013$; accepted December $10^{\text {th }}, 2013$

Copyright (C) 2013 Mimoza Basholli-Salihu et al. This is an open access article distributed under the Creative Commons Attribution License, which permits unrestricted use, distribution, and reproduction in any medium, provided the original work is properly cited. In accordance of the Creative Commons Attribution License all Copyrights (C) 2013 are reserved for SCIRP and the owner of the intellectual property Mimoza Basholli-Salihu et al. All Copyright (C) 2013 are guarded by law and by SCIRP as a guardian.

\begin{abstract}
The effects of cellobiose, fructooligosaccharide and their combination on fermentation of skim milk by probiotic Bifidobacterium infantis were evaluated using mean doubling time as a parameter for sustaining growth. The lowest mean doubling time was observed for $2 \%$ cellobiose, followed by a combination of $2 \%$ fructooligosaccharide (FOS) with $2 \%$ cellobiose, while during storage at $4{ }^{\circ} \mathrm{C}$ for 4 weeks of fermented milk, no significant differences were observed between fermented milk supplemented with $2 \%$ cellobiose and $2 \%$ FOS. The highest viability retention during storage was observed for the combination of the two prebiotics, cellobiose and FOS. The results indicate that, in milk supplemented with cellobiose or a combination of cellobiose and FOS, Bifidobacterium infantis remain viable during 4 weeks of storage, suggesting the usefulness of cellobiose as a prebiotic ingredient in fermented products involving bifidobacteria.
\end{abstract}

Keywords: Bifidobacteria; Cellobiose; Synbiotic; Fermented Milk; Viability

\section{Introduction}

Dairy functional products containing probiotics, especially fermented milk, have attracted increased interest for prevention of gastrointestinal disorders [1]. Consumption of probiotic dairy products has been shown to exert benefits to human health [2,3]. Probiotics are defined as "live microorganisms which when administered in sufficient numbers, confer a health benefit to the host" [4]. Thus, probiotics (Lactobacillus spp. and Bifidobacterium spp.) are more and more frequently used for production of fermented dairy products. To provide potential therapeutic benefits, probiotics should remain viable at concentrations $\geq 6 \log \mathrm{CFU} \cdot \mathrm{g}^{-1}$ before consumption [5]. During production and storage of fermented dairy products, the probiotics are exposed to several stresses such as low $\mathrm{pH}$, presence of oxygen, cold and osmotic stress [6-8].

The improvement of growth and viability in fermented foods may be achieved by the use of growth enhancers

\footnotetext{
${ }^{*}$ Corresponding author.
}

such as prebiotics [9-11].

Prebiotics are defined as "non-digestable carbohydrates that beneficially affect the host by selectively stimulating the growth and/or activity of colonic microflora" [12]. Several groups of oligosaccharides have been used for improving the survival of probiotics [13-15]. In addition to their effect on viability retention of probiotics, prebiotics have been shown to increase the growth of lactobacilli and bifidobacteria in the caecum and large intestine. Furthermore, the prevention of travelers' diarrhea, alleviation of irritable bowel syndrome symptoms and reduction of risk factors for colon cancer have been documented to be related to prebiotics intake [16-18].

Fructooligosaccharides are widely used as prebiotics to improve the growth and viability of bifidobacteria in dairy foods $[8,9,19]$. Recently, interest in new potential prebiotics such as cellooligosaccharides has increased [20,21].

Bioavailability of cellobiose in humans has been evaluated using cellobiose tolerance tests and breath hydrogen excretion [22]; it has been observed that after inges- 
tion, cellobiose can be fermented by gut microflora. Furthermore, the ingested cellobiose could not be hydrolyzed by the enzymes in the small intestine, reaching the colon undigested [23-25].

Few studies have appeared on the effect of cellobiose on growth rates of Bifidobacterium spp. [20]. According to these reports, cellobiose has a higher prebiotic index than FOS [26].

To the best of our knowledge, no study has been reported on the effect of cellobiose on growth and viability of probiotics in fermented milk.

The aim of the present study was to investigate the effects of cellobiose as food ingredient on the growth and fermentation profiles of Bifidobacterium infantis UV16PR in comparison to fructooligosaccharide as widely used prebiotic. In addition, the effect of prebiotics alone or in combination on cell viability retention during storage was investigated.

\section{Materials and Methods}

\subsection{Bacterial Growth and Culture Preparation}

Bifidobacterium infantis (UV16PR) was kindly by Medipharm (Kågeröd, Sweden). The cells were activated and grown in Reinforced Clostridial Medium (RCM, Oxoid Ltd., Hampshire, UK) by incubation at $37^{\circ} \mathrm{C}$ in an anaerobic jar using Anaerogen kits (Oxoid Ltd., Hampshire, UK).

\subsection{Growth of Bifidobacterium infantis in Skim Milk in the Presence of Glucose or Prebiotics}

Cellobiose and FOS were used as prebiotics. Glucose was used as reference. The prebiotics were added to $12 \%$ (w/v) skim milk, reconstituted according to the manufacturer's instructions, to give a final concentration of $2 \%(\mathrm{w} / \mathrm{v})$. The supplemented reconstituted skim milk (RSM) was divided in sterile tubes and pasteurized at $70^{\circ} \mathrm{C}$ for $15 \mathrm{~min}$, according to the method described earlier [19]. Control samples did not contain glucose or prebiotics. A 5\% inoculation of cells was used to determine the growth. The inoculated samples were incubated under anaerobic conditions in an anaerobic chamber using Anaerogen kits at $37^{\circ} \mathrm{C}$ for $48 \mathrm{~h}$. For determination of growth, aliquots of $1 \mathrm{ml}$ were withdrawn immediately after inoculation (time $0 \mathrm{~h}$, baseline) and after $12 \mathrm{~h}, 24 \mathrm{~h}$, and $48 \mathrm{~h}$. Growth was measured by enumeration of cells using pour plate count methods. Aliquots of $1 \mathrm{ml}$ were serially diluted and then spread onto Reinforced Clostridial Agar (RCA) plates, incubated anaerobically at $37^{\circ} \mathrm{C}$ for $48 \mathrm{~h}-72 \mathrm{~h}$. The mean doubling time $\left(\mathrm{T}_{\mathrm{d}}\right)$ was calculated using Equation (1) according to Shin et al. [19] with minor modification.

$$
\mathrm{T}_{\mathrm{d}}=\ln 2 / \mu
$$

where $\mu$-specific growth rate is calculated using Equation (2) as follows:

$$
\mu=\left(\ln C_{2}-\ln C_{1}\right) /\left(t_{2}-t_{1}\right)
$$

where

$C_{2}$ - colony forming units per milliliter $(\mathrm{CFU} / \mathrm{ml})$ determined at time $t_{2}$;

$C_{1}$ - colony forming units per milliliter $(\mathrm{CFU} / \mathrm{ml})$ determined at time $t_{1}$.

\subsection{Stability of Cells during Storage}

Bifidobacterium infantis cells were cultured in RCM supplemented with $2 \%$ cellobiose, $2 \%$ FOS or a combination of $2 \%$ cellobiose and $2 \%$ FOS; after $24 \mathrm{~h}$ fermentation in anaerobic conditions, the samples were stored at $4^{\circ} \mathrm{C}$ for 4 weeks. Aliquots of $1 \mathrm{ml}$ were serially diluted using $9 \mathrm{ml}$ of sterile phosphate buffer. Viable cells were determined after $24 \mathrm{~h}$ fermentation (before storage) and after 4 weeks of storage, using plate count methods. The viability during storage was expressed as percent, calculated using Equation (3) as follows:

$$
\text { Viability }[\%]=N * 100 / N_{0}
$$

$N$-number of viable cells after 4 weeks of storage (CFU/ml);

$N_{0}$-number of viable cells before storage (CFU/ml).

\section{4. pH Measurement}

$\mathrm{pH}$ was determined before and after $24 \mathrm{~h}$ fermentation and after 4 weeks of storage at $4^{\circ} \mathrm{C}$, using a $\mathrm{pH}$ meter (Hanna Instruments, Woonsocket, RI, USA), calibrated with fresh $\mathrm{pH} 4.0$ and 7.0 standard buffers.

\subsection{Statistical Analysis}

All experiments were performed in triplicate. Statistical analysis was performed using GraphPad Prism (GraphPad Software, San-Diego, USA) by one-way ANOVA, and Tukey test cross-comparing all study groups. Values of $\mathrm{p}<0.05$ were considered significant.

\section{Results and Discussion}

\subsection{Growth of Bifidobacterium infantis in Skim Milk Supplemented with Glucose or Prebiotics}

The effectiveness of prebiotics toward growth promotion of Bifidobacterium infantis was evaluated by measuring mean doubling time. The mean doubling times (expressed in minutes) of Bifidobacterium infantis in RSM containing $2 \%(\mathrm{w} / \mathrm{v})$ cellobiose, $2 \%$ FOS, or a combination of $2 \%(\mathrm{w} / \mathrm{v})$ cellobiose and $2 \%(\mathrm{w} / \mathrm{v})$ FOS are shown in Figure 1. 


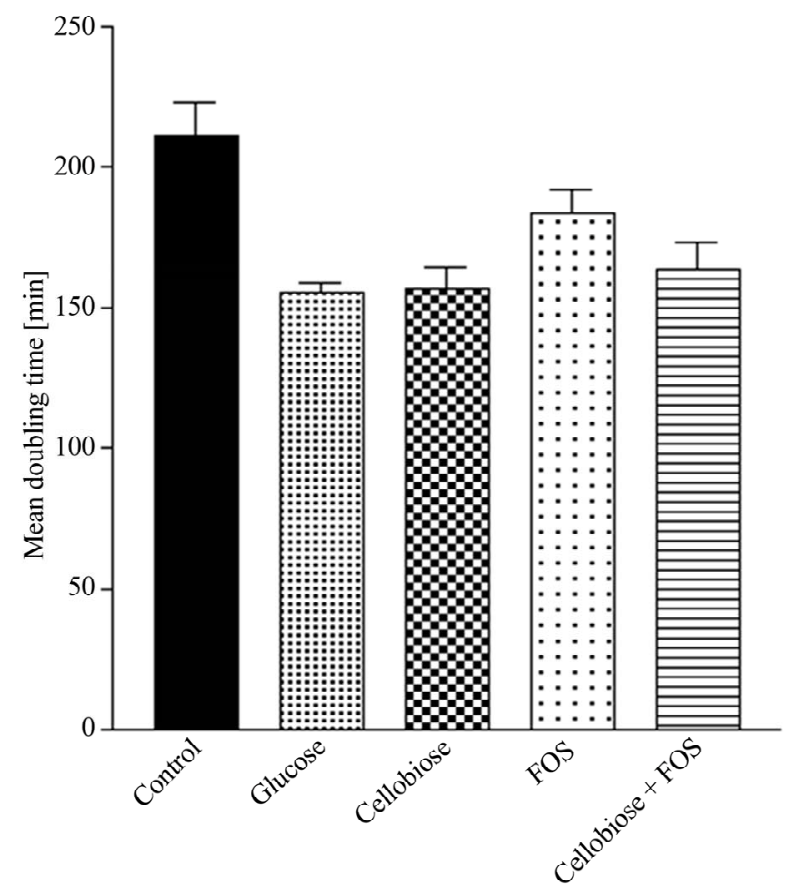

Figure 1. Mean doubling times (in minutes) of Bifidobacterium infantis grown in skim milk containing prebiotics (cellobiose and fructooligosaccharides-FOS) or glucose. Control represents samples without addition of any carbon source. Each bar represent means \pm standard deviation, $n=$ 3. Determined by Tukey test cross-comparing all study groups. Values of $p<0.05$ were considered significant.

This is the first study to show the effectiveness of cellobiose-supplemented milk on the growth of probiotics. The fructooligosaccharides have been shown to reduce the mean doubling times of several Bifidobacterium spp. and Lactobacillus spp. [9,19,27].

In the present study, it was observed that in the presence of cellobiose, or FOS, or their combination the mean doubling time was significantly lower compared to the control $(\mathrm{p}<0.001)$.

The $2 \%$ supplementation with cellobiose was shown to be the most effective for growth of $B$. infantis in milk, with a mean doubling time of $157.2 \mathrm{~min}$, followed by a combination of cellobiose and FOS with $163.85 \mathrm{~min}$ and FOS with a mean doubling time of $183.66 \mathrm{~min}$.

Mean doubling time in cellobiose supplemented milk was significantly lower compared to FOS ( $p<0.05)$, but no significant difference was observed compared to the combination of cellobiose and FOS ( $p>0.05)$.

The effect of FOS and cellobiose on the growth of $\mathrm{Bi}$ fidobacterium spp. in milk during $48 \mathrm{~h}$ of fermentation was shown in Figure 2. To the best of our knowledge, the effect of cellobiose on the growth of Bifidobacterium spp. in milk has not been studied so far. The cellobiose and cellodextrins have been shown to increase the growth of Bifidobacterium spp. to different extents in growth medium [20,28].

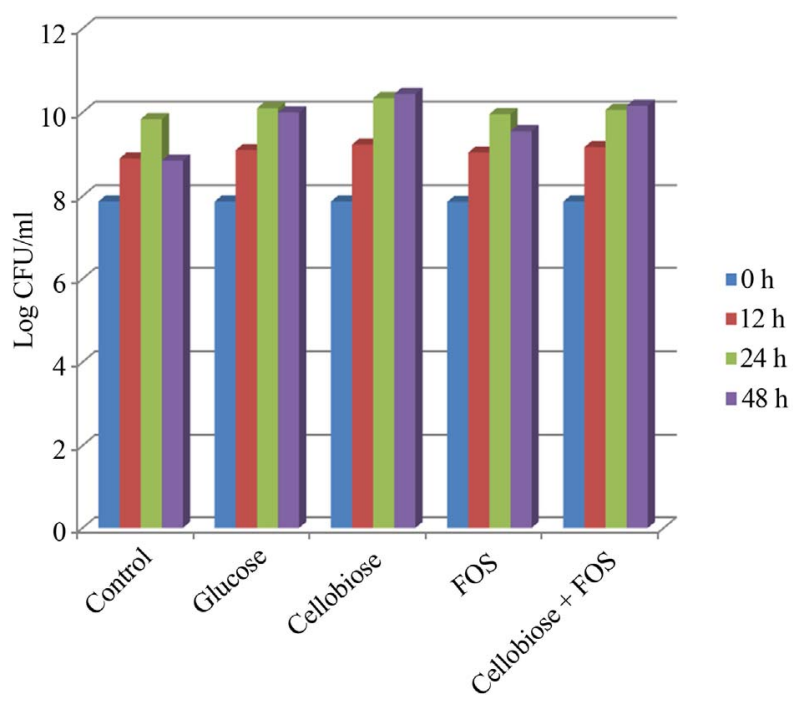

Figure 2. Growth of Bifidobacterium infantis in skim milk containing glucose, cellobiose, fructooligosaccharide (FOS), or a combination of cellobiose and FOS, during $48 \mathrm{~h}$ of incubation.

Even though the mean doubling time with cellobiose was significantly lower compared to FOS, the differences decreased during storage. This can be attributed to the higher substrate preferences for cellobiose compared to FOS which is in accordance to our previous work (data not shown).

Thus, fermented milk with Bifidobacterium infantis in the presence of cellobiose can be used as a functional food product.

Differences in carbohydrate utilization can be attributed to differences in enzyme activities, responsible for metabolizing the specific carbohydrates [20,29].

Similar results were reported earlier [16], who found that carbohydrates with short chains are metabolized faster than longer chain oligosaccharides.

The differences observed on the growth-promoting properties of different carbohydrates on various probiotics can be attributed to differences in transport systems available, to the bacterial cells and to the presence and localization of enzymes responsible for fermentation of certain carbohydrates [30]. Furthermore the type of the linkage between monomers and the degree of polymerization of the carbohydrate influence the growth of the probiotics [31].

\subsection{Viability of Cells during Storage in Fermented Milk}

The viability of Bifidobacterium infantis was decreased during storage in fermented milk (Figure 3).

As shown in the figure, the presence of prebiotics significantly increased the viability of cells during storage. These results are in accordance to those previous re- 


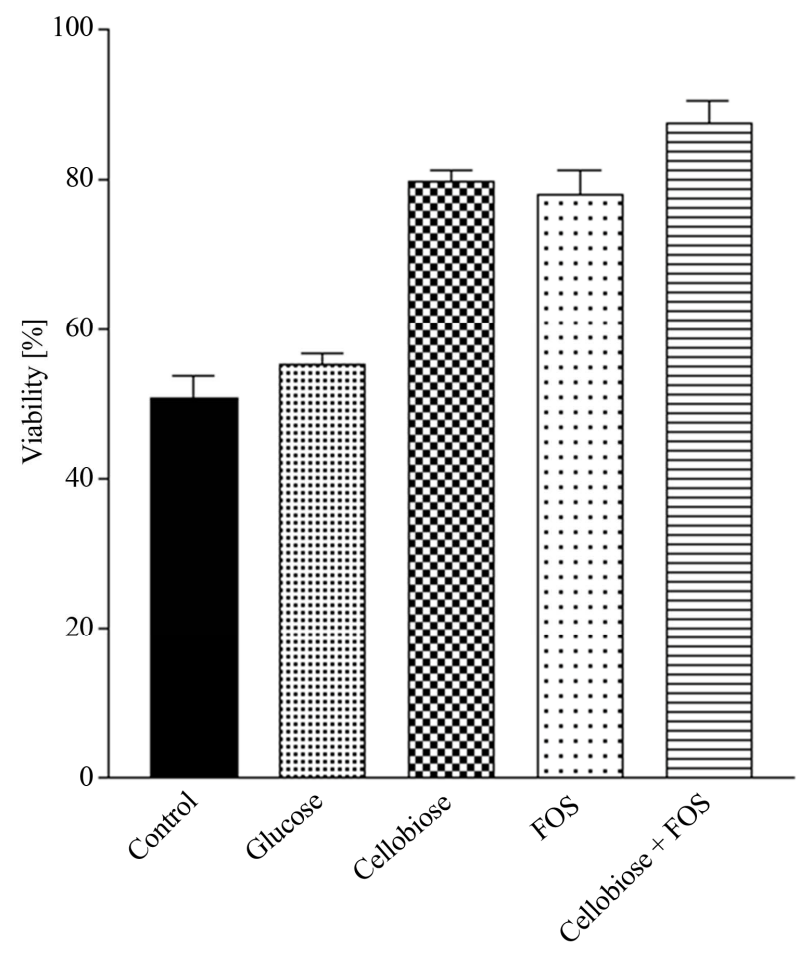

Figure 3. Viability of Bifidobacterium infantis grown in skim milk supplemented with glucose, cellobiose, fructooligosaccharide (FOS) or a combination of cellobiose and FOS, after storage for 4 weeks at $4^{\circ} \mathrm{C}$. Each bar represent means \pm standard deviation, $n=3$. Determined by Tukey test crosscomparing all study groups. Values of $p<0.05$ were considered significant.

ported [9]. The loss of viability during storage can be attributed the presence of oxygen, low $\mathrm{pH}$, cold, and osmotic stresses [6].

In skim milk without prebiotics, the viability of cells was $50 \%$, which is not in accordance to the results shown by [32] who observed an $83 \%$ loss of viability during 4 weeks of storage of Bifidobacterium infantis. Furthermore, studies reported earlierobserved $29.66 \%$ viability of cells during storage of Bifidobacterium infantis [9]. These differences may be attributed to the different subspecies of Bifidobacterium infantis used. In our study, the selected strain of Bifidobacterium infantis was shown to exert high $\beta$-galactosidase activity that is important for utilization of the lactose present in milk.

These results suggest that the appropriate prebiotic for a single probiotic strain depends on the enzyme activity toward certain prebiotics.

No significant differences were observed in viability during storage in the presence of $2 \%$ FOS or $2 \%$ cellobiose ( $\mathrm{p}>0.05$ ), namely $79.9 \%$ and $77.4 \%$, respectively, while significantly higher viability was observed in the presence of the combination cellobiose + FOS $(p<0.01)$, namely $87.6 \%$.

Cellobiose was shown to be significantly more effec- tive compared to FOS on the growth of B. infantis during fermentation of skim milk, while no significant differences in viability during storage were observed. In the present study, FOS was shown to be effectively enhancing the growth of $B$. infantis, but the utilization is slower compared to cellobiose so that its effect is more evident during storage. The rate of utilization of carbohydrates is influenced by the degree of polymerization of oligosaccharides and the type of linkage between monomer units in the sugar [31].

Some of the differences in enzyme activities responseble for metabolizing the specific carbohydrates, leading to differences in carbohydrate utilization, have been described $[20,29]$.

The $\mathrm{pH}$ values of the milk were determined before fermentation, after $24 \mathrm{~h}$ of fermentation and after 4 weeks of storage of fermented milk at $4^{\circ} \mathrm{C}$. The $\mathrm{pH}$ values are shown in Figure 4.

Before fermentation the $\mathrm{pH}$ values ranged from 6.25 6.27 .

During fermentation a strong decrease of $\mathrm{pH}$ was observed, with values ranging from $4.39-4.59$ due to the formation of acetic and lactic acids which are the products of sugar metabolization $[9,19]$. The lower decrease during the storage can be attributed to lower metabolic activity of cells under the storage conditions (low pH and $4^{\circ} \mathrm{C}$ ), resulting in values from $4.09-4.29$. Similar results were observed on previous reported studies $[9,19]$.

\section{Conclusion}

The presence of cellobiose and FOS supports the growth of Bifidobacterium infantis in skim milk. Supplementation with cellobiose led to significantly lower mean doubling times compared to controls, sucrose and FOS, while

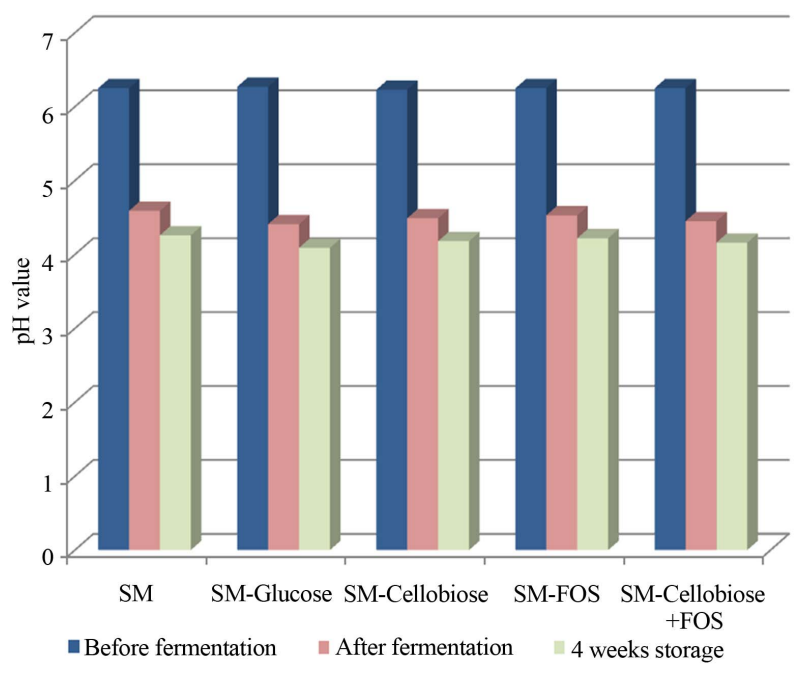

Figure 4. The changes of $\mathrm{pH}$ value after fermentation and storage at $4^{\circ} \mathrm{C}$ of skim milk (SM) fermented by $B$. infantis, in the presence of different carbon sources. 
during storage of fermented milk their effectiveness on viability was shown to be comparable. Thus cellobiose alone or in combination with FOS is suitable for synbiotic combinations with Bifidobacterium infantis for enhancement of quality of fermented milk.

\section{Acknowledgements}

The authors gratefully thank the Austrian Ministry of Science and Technology (BMWF-Bertha von Suttner program) for providing scholarship to Mimoza Basholli-Salihu.

\section{REFERENCES}

[1] O. N. Donkor, S. L. I. Nilmini, P. Stolic, T. Vasiljevic and N. P. Shah, "Survival and Activity of Selected Probiotic Organisms in Set-Type Yoghurt during Cold Storage," International Dairy Journal, Vol. 17, No. 6, 2007, pp. 652-657. http://dx.doi.org/10.1016/j.idairyj.2006.08.006

[2] M. De Vrese and P. R. Marteau, "Probiotics and Prebiotics: Effects on Diarrhea," Journal of Nutrition, Vol. 137, No. 3, 2007, pp. 803S-811S.

[3] M. de Vrese, A. Stegelmann, B. Richter, S. Fenselau, C. Laue and J. Schresenmeir, "Probiotics-Compensation for Lactase Insufficiency," American of Journal and Clinical Nutrition, Vol. 73, No. 2, 2001, pp. 421-429.

[4] FAO/WHO, "Health and Nutritional Properties of Probiotics in Food including Powder Milk with Live Lactic Acid Bacteria," Report of a Joint FAO/WHO Expert Consultation on Evaluation of Health and Nutritional Properties of Probiotics in Food Including Powder Milk with Live Lactic Acid Bacteria, Córdoba, 1-4 October 2001. http://www.who.int/foodsafety/publications/fs managem ent/en/probiotics.pdf

[5] D. Roy, "Technological Aspects Related to the Use of Bifidobacteria in Dairy Products," Lait, Vol. 85, No. 1-2, 2005, pp. 39-56. http://dx.doi.org/10.1051/lait:2004026

[6] D. Granato, G. F. Branco, A. G. Cruz, J. A. F. Faria and N. P. Shah, "Probiotic Dairy Products as Functional Foods," Comprehensive Review of Food Science and Food Safety, Vol. 9, No. 5, 2010 pp. 455-470. http://dx.doi.org/10.1111/j.1541-4337.2010.00120.x

[7] R. P. S. Oliveira, P. Perego, M. N. Oliveira and A. Converti, "Effect of Inulin as Prebiotic and Synbiotic Interactions between Probiotics to Improve Fermented Milk Firmness," Journal of Food Engineering, Vol. 107, No. 1, 2011, pp. 36-40.

http://dx.doi.org/10.1016/j.jfoodeng.2011.06.005

[8] L. C. Maganha, R. E. Rosim, C. H. Corassin, A. G. Cruz, J. A. F. Faria and C. A. F. Oliveira, "Viability of Probiotic Bacteria in Fermented Skim Milk Produced with Different Levels of Milk Powder and Sugar," International Journal of Dairy Technology, 2013. http://dx.doi.org/10.1111/1471-0307.12087

[9] F. A. Bruno, W. E. Lankaputhra and N. P. Shah, "Growth, Viability and Activity of Bifidobacterium spp. in Con- taining Prebiotics," Journal of Food Science, Vol. 67, No. 7, 2002, pp. 2740-2744.

http://dx.doi.org/10.1111/j.1365-2621.2002.tb08807.x

[10] B. M. Corcoran, R. P. Ross, G. F. Fitzgerald and C. Stanton, "Comparative Survival of Probiotic Lactobacilli Spray-Dried in the Presence of Prebiotic Substances," Journal of Applied Microbioloy, Vol. 96, No. 5, 2004, pp. 1024-1039. http://dx.doi.org/10.1111/j.1365-2672.2004.02219.x

[11] P. Capela, T. K. C. Hay and N. P. Shah, "Effect of Cryoprotectants, Prebiotics and Microencapsulation on Survival of Probiotic Organisms in Yoghurt and FreezeDried Yoghurt," Food Research International, Vol. 39, No. 2, 2006, pp. 203-211. http://dx.doi.org/10.1016/j.foodres.2005.07.007

[12] T. S. Manning and G. R. Gibson, "Prebiotics," Best Practice and Research Clinical Gastroenterology, Vol. 18, No. 2, 2004, pp. 287-298.

http://dx.doi.org/10.1016/j.bpg.2003.10.008

[13] G. R. Gibson, H. M. Probert, J. Van Loo, R. A. Rastall and M. B. Roberfroid, "Dietary Modulation of the Human Colonic Microbiota: Updating the Concept of Prebiotics," Nutrition Research Reviews, Vol. 17, No. 2, 2004, pp. 259-275. http://dx.doi.org/10.1079/NRR200479

[14] M. Roberfroid, "Prebiotics: The Concept Revisited," Journal of Nutrition, Vol. 137, 2007, pp. 830S-837S.

[15] R. G. Crittenden, L. F. Morris, M. L. Harvey, L. T. Tran, H. L. Mitchell and M. J. Playne, "Selection of a Bifidobacterium Strain to Complement Resistant Starch in a Symbiotic Yoghurt," Journal of Applied Microbiology, Vol. 90, No. 2, 2001, pp. 268-278. http://dx.doi.org/10.1046/j.1365-2672.2001.01240.x

[16] J. H. Cummings, S. Christi and T. J. Cole, "A Study of Fructooligosaccharides in the Prevention of Travellers' Diarrhea," Alimentary Pharmacology and Therapeutics, Vol. 15, No. 8, 2001, pp. 1139-1145. http://dx.doi.org/10.1046/j.1365-2036.2001.01043.x

[17] E. M. Quigley, "Prebiotics and Probiotics; Modifying and Mining the Microbiota," Pharmacological Research, Vol. 61, No. 3, 2010, pp. 213-218. http://dx.doi.org/10.1016/i.phrs.2010.01.004

[18] E. M. Quigley, "Prebiotics and Probiotics: Their Role in the Management of Gastrointestinal Disorders in Adults," Nutrition in Clinical Practice, Vol. 27, No. 2, 2012, pp. 487-492. http://dx.doi.org/10.1177/0884533611423926

[19] H.-S. Shin, J.-H. Lee, J. J. Pestka and Z. Ustunol, "Growth and Viability of Commercial Bifidobacterium spp in Skim Milk Containing Oligosaccharides and Inulin," Journal of Food Microbiology and Safety, Vol. 65, No. 5, 2000, pp. 884-887.

[20] K. Pokusaeva, M. O'Connell-Motherway, A. Zomer, J. MacSharry, G. F. Fitzgerald and D. van Sinderen, "Cellodextrin Utilization by Bifidobacterium breve UCC2003," Applied and Environmental Microbiology, Vol. 77, No. 5, 2011, pp. 1681-1690. http://dx.doi.org/10.1128/AEM.01786-10

[21] S.-K. Yeo and M.-T. Liong, "Effect of Prebiotics on Viability and Growth Characteristics of Probiotics in Soymilk," Journal of the Science of Food and Agriculture, 
1306 The Use of Cellobiose and Fructooligosaccharide on Growth and Stability of Bifidobacterium infantis in Fermented Milk

Vol. 90, No. 2, 2011, pp. 267-275. http://dx.doi.org/10.1002/jsfa.3808

[22] S. Nakamura, T. Oku and M. Ichinose, "Bioavailability of Cellobiose by Tolerance Test and Breath Hydrogen Excretion in Humans," Nutrition, Vol. 20, No. 11, 2004, pp. 979-983. http://dx.doi.org/10.1016/j.nut.2004.08.005

[23] M. Kim and D. F. Day, "Optimization of Oligosaccharide Synthesis from Cellobiose by Dextransucrase," Applied Biochemistry and Biotechnology, Vol. 148, No. 1-3, 2008, pp. 189-198.

http://dx.doi.org/10.1007/s12010-007-8042-x

[24] M. Satouchi, T. Watanabe, S. Wakabayashi, K. Ohokuma, T. Koshijima and M. Kuwahara, "Digestibility, Absorptivity and Physiological Effects of Cellooligosaccharides in Human and Rat," Nippon Eiyo Shokuryo Gakkaishi, Vol. 49, No. 3, 1996, pp. 143-148. http://dx.doi.org/10.4327/jsnfs.49.143

[25] T. Watanabe, "Development of Physiological Functions of Cellooligosaccharides," Cellulose Communications, Vol. 5, No. 2, 1998, pp. 91-97.

[26] M. L. Sanz, G. R. Gibson and R. A. Rastall, "Influence of Disaccharide Structure on Prebiotic Selectivity in Vitro," Journal of Agricultural and Food Chemistry, Vol. 53, No. 13, 2005, pp. 5192-5199. http://dx.doi.org/10.1021/jf050276w

[27] A. R. Desai, I. B. Powell and N. P. Shah, "Survival and Activity of Probiotics Lactobacilli in Skim Milk Containing Prebiotics," Journal of Food Microbiology and
Safety, Vol. 69, No. 3, 2004, pp. 57-60.

[28] L. Roncaglia, A. Amaretti, S. Raimondi, A. Leonardi and M. Rossi, "Role of Bifidobacteria in the Activation of the Lignin Secoisolariciresinol Diglucoside," Applied Microbiology and Biotechnology, Vol. 92, No. 1, 2011, pp. 159-168. http://dx.doi.org/10.1007/s00253-011-3338-8

[29] S.-K. Yeo and M.-T. Liong, "Effect of Prebiotics on Viability and Growth Characteristics of Probiotics in Soymilk," Journal of the Science of Food and Agriculture, Vol. 90, No. 2, 2010, pp. 267-275. http://dx.doi.org/10.1002/jsfa.3808

[30] C. L. Vernazza, G. R. Gibson and R. A. Rastall, "Carbohydrate Preference, Acid Tolerance and Bile Tolerance in Five Strains of Bifidobacterium," Journal of Applied Microbiology, Vol. 100, No. 4, 2006, pp. 846-853. http://dx.doi.org/10.1111/j.1365-2672.2006.02832.x

[31] R. A. Rastall, G. R. Gibson, H. S. Gill, F. Guarner, T. R. Klaenhammer, B. Pot, G. Reid, I. R. Rowland and M. E. Sanders, "Modulation of the Microbial Ecology of the Human Colon by Probiotics, Prebiotics and Synbiotics to Enhance Human Health: An Overview of Enabling Science and Potential Applications," FEMS Microbiology Ecology, Vol. 52, No. 2, 2005, pp. 145-152. http://dx.doi.org/10.1016/j.femsec.2005.01.003

[32] W. E. V. Lankaputhra, N. P. Shah and M. Britz, "Survival of Bifidobacteria during Refrigerated Storage in Presence of Acid and Hydrogen Peroxide," Milchwissenschaft, Vol. 17, 1996, pp. 65-70.

\author{
Abbreviations \\ FOS: Fructooligosaccharide \\ RCM: Reinforced Clostridial Medium \\ RCA: Reinforced Clostridial Agar
}

